\title{
Crib death: further support for the concept of fatal cardiac electrical instability as the final common pathway
}

\author{
Giulia Ottaviani $^{\mathrm{a}, \mathrm{b}, *}$, Luigi Matturri ${ }^{\mathrm{a}}$, Lino Rossi ${ }^{\mathrm{a}}$, Thomas N. James ${ }^{\mathrm{b}}$ \\ ${ }^{a}$ Institute of Pathology, University of Milan, Via della Commenda 19, 20122 Milan, Italy \\ ${ }^{\mathrm{b}}$ Department of Medicine and Department of Pathology, at the University of Texas Medical Branch in Galveston, Galveston, TX, USA
}

Received 25 July 2002; received in revised form 20 November 2002; accepted 15 January 2003

\begin{abstract}
This work intends to be a review of the current status of knowledge on the cardiac conduction system in the crib death as well as remaining challenges, including reflections upon authors' personal works as well as many studies by others. The cardiac conduction system findings of resorptive degeneration, His bundle dispersion, Mahaim fibers, cartilaginous meta-hyperplasia, persistent fetal dispersion, left sided His bundle, hemorrhage of the atrio-ventricular junction, septation of the bifurcation, atrio-ventricular node dispersion, sinus node hypoplasia, Zahn node, His bundle hypoplasia, atrio-ventricular node and His bundle dualism are hereby discussed by the authors. The cardiac hypotheses postulating that crib death could be due to lethal cardiac arrhythmias or heart block were considered of great interest in the 1970s. After a general abandon of the conduction studies in crib death, the cardiac concept of crib death is gathering a renewed interest, as well as the occurrence of infantile junctional tachycardia. Both the morphological and functional derangement underlying crib death remain poorly understood, assuring that it remains to be a major medical and social problem. Despite the non-specificity of most of the cardiac conduction findings in crib death, we believe that they, in association with altered neurovegetative stimuli, could underlie potentially malignant arrhythmias, providing a morphologic support for the cardiac concept of crib death.
\end{abstract}

(C) 2003 Elsevier Ireland Ltd. All rights reserved.

Keywords: Cardiac conduction system; Crib death; Resorptive degeneration; Accessory pathways

He [King David] answered, "While the child was still alive, I fasted and I wept. I thought, "Who knows? The Lord may be gracious to me and let the child live." But now that he is dead, why should I fast? Can I bring him back again? I will go to him, but he will not return to me. [2 Samuel 12: 22,23].

\section{Introduction}

Sudden and unexpected death of a young baby is surely one of the most emotional tragedies that any parent can experience. This has understandably led to a continued and growing concern with search for an explanation with the goal of being able to either predict, quickly diagnose and even treat the child when time permits. Poignantly and

Abbreviations: AV, atrio-ventricular; TUNEL, TdT-mediated dUTP nick end labeling; AI, apoptotic index

* Corresponding author. Tel.: +39-02-541-9543; fax: +39-02-541-9538.

E-mail address: giulia.ottaviani@unimi.it (G. Ottaviani). perhaps most sadly, the death occurs too often when no one is around, with the dead baby only being discovered later.

Crib death is sudden, unexpected, and unexplained just by careful study, and represents a multifaceted problem [1-4]. Its prevention, according to the American Academy of Pediatrics, is primarily based on having infants sleep in a supine position, rather than in the previously recommended prone position [5]. In the last few years there has been a $50 \%$ decline in crib death's incidence due to the identification of specific environmental risk factors, particularly the prone position and maternal smoking [6]. Several previously acknowledged instances of crib death have been demonstrated to be examples of infanticide [7-9]. The prevalence of nonnatural death among children presenting as crib death leads some to believe that every unexpected child death should be treated as homicide until proved otherwise [8]. The pathogenesis of crib death remains still largely unknown and is controversial with a wide spectrum of hypotheses: the cardiac (arrhythmogenic) [10-23], the respiratory (apnea and/or suffocation) [24-26], and the 
visceral dyskinetic (glottic spasm and/or gastroesophageal reflex) theories [26,27]. Recently, emphasis has been given to the autonomic nervous supply to the cardio-respiratory apparatus [28-31]. The pathogenesis of crib death is still largely unknown and its still high frequency has led to continuous research to uncover the anatomo-pathological substrates.

The involvement of conducting tissue has been for years a controversial issue in cardiac pathology of crib death. The crib death cases do not present any abnormality of the ordinary myocardium, while the core of the heart, where cardiac rhythm arises and spreads, represents an insight to the solution of the problem. Most pathologists do not consider very small lesions in the general myocardium as having any functional significance, whereas, because they are not experienced in looking at the cardiac conduction system, they fail to understand how crucially important a lesion with maximal dimensions of $1 \mathrm{~mm}$ could be in the cardiac conduction system.

In the 1970s several authors focused the study of crib death on the conducting tissue $[11,17,19,20,32-38]$. The most common finding discussed was the postnatal morphogenesis first defined by James as "resorptive degeneration" [17], consisting of areas of degeneration, cell death mainly by apoptosis $[10,39,40]$, and replacement fibrosis, beginning about 1 or 2 weeks after birth [10], and being usually completed in the first year of life $[17,41]$. James' concept has been confirmed by Ferris [20], Marino and Kane [42] and Rossi et al. [1,4,22,43], but the validity of his findings has been questioned by other investigators $[11,21,33,44]$. Since this finding was present in both groups, the studies were considered by some authors not conclusive and thus abandoned. Despite the cardiac hypothesis of crib death remains controversial [45], nowadays, the concept that it may be related to lethal cardiac arrhythmias or heart block due to structural conduction abnormalities seems to focus a renewed interest, as well as the occurrence of infantile junctional tachycardia $[10,12-16,46,47]$.

This work intends to be a review of the current status of knowledge on the cardiac conduction system in crib death as well as remaining challenges, including reflections upon authors' personal works as well as many studies by others. An adjourned re-examination of the cardiac conduction hypothesis of crib death, to the light of a systematic histopathological analysis, even if will not be able to resolve this complex problem, it can be useful for a better organization of the research. Preliminary findings have been reported in abstract form [48].

\section{Material and methods}

Here is described the technique devised by one of the present author (L.R.), according to the autopsy protocol usually followed by the Institute of Pathology, University of Milan in case of sudden and unexpected infant death
$[1,22,43]$. At the general autopsy, before focusing on the heart, any extracardiac cause of death should be ruled out. The well-known procedure of measuring heart size and weight should not be omitted, and the values measured should be compared with the normal values for infants of that length and age $[49,50]$. After the presence of gross cardiac malformations are excluded, the origin of the coronary arteries should be carefully inspected. The heart is regularly examined for pathologic changes in the atria, septa, ventricles, pericardium, endocardium and coronary arteries. Samples of the myocardium are stained with hematoxylin-eosin and trichromic Heidenhain (azan). Histological observations are focused on the cardiac conduction system, which, though fairly constant in layout and structure, is subject to noteworthy individual variations [1]; hence, histological examination by serial sections is expected to provide the necessary data, on both topography and pathology of the specialized tissue [43]. The cardiac conduction system is removed in two blocks for paraffin embedding. Block 1 consisted of a portion of the right atrial wall including the lateral half of the funnel of the superior vena cava, sulcus and crista terminalis. This first block includes the sino-atrial node, its atrial approaches, the crista terminalis (with the upper $2 / 3$ of the posterior internodal tract, the proximal part of the middle and anterior tracts), and the sino-atrial node's ganglionated plexus. Block 2 consists of the lower portion of the atrial septum, the trigonum fibrosus, and anterior contour of the coronary sinus and the upper $2 / 3$ of the ventricular septum. This second block contains the atrioventricular node, His bundle, bifurcation, and bundle branches. For the histological examination of the cardiac conduction system the two blocks are cut serially at intervals of $40 \mu \mathrm{m}$ (levels) $[1,43]$. For each level three sections of $8 \mu \mathrm{m}$ were saved: two of these were stained alternately with hematoxylin-eosin and trichromic Heidenhain (azan), and one is stained immunohistochemically using in situ labeling of fragmented DNA (TUNEL) [51]. All intervening sections are kept and stained as deemed necessary. For each heart, the average number of histologic sections stained and examined is about 200. The tridimensional reconstruction of the cardiac conduction system is obtained by following it on the series of bidimensional slides $[1,43]$. The techniques devised by our Institute are described on the following web site: http://users.unimi.it/ pathol/sids/tecnica_e.html.

\section{Discussion}

Crib death represents a tragic enigma, one of the main open issues in the social-medical and scientific setting of modern medicine. It is still frequent despite the progress in the field of maternal-infantile assistance. Despite a wide spectrum of proposed theories, its etiology remains uncertain and it is one of the major social and health problems of 
today's medicine not yet resolved. Inherent emotive consequences among the family [3] and the social cost are heavy, especially considering the early loss of many potentially productive individuals.

On the histopathological plane, although the diagnosis of crib death is of exclusion, there are several findings which are of value in diagnosis and suggest new avenues for research: brainstem abnormalities [28,29,31,52], mediastinal ganglionic-paraganglionic plexuses changes [2,53], vagal immaturity $[2,4]$, hyper or hypotrophy of the carotid bodies $[2,4,54]$, and developmental changes of the cardiac conduction system [32-34,40,41,55-62].

Emphasis has been given to the autonomic nervous supply to the cardio-respiratory apparatus [28-31]. Particularly, much attention has been directed at the arcuate nucleus that is postulated to be involved in chemoreception, respiratory and blood pressure responses [63]. The arcuate nucleus hypoplasia seems to play an important role among the causative factors of crib death, as well as of unexpected late fetal death $[31,52,64]$. However, these centrally mediated ventilatory and cardiovascular reflex/control mechanisms most often have peripheral originating sites within the heart itself. Harper and Bandler [65] reported decreased receptor binding in the brainstem of children dying suddenly and unexpectedly, consistent with primary cardiovascular failure. By these two neuroscientists the heart failure was referred as a fatal inability of the heart to function appropriately, thus encouraging a new focus on the heart as the probable final common pathway in crib death.

There is much that still needs to be established concerning the arrangement of the cardiac conduction system in infant hearts [45]. The morphologic post mortem study of the conducting tissue in all cases of sudden death in infancy is based on the cardiac concept of crib death, which postulates that it could be due to lethal cardiac electrical instability. This study brings to James' original observations concerning postnatal morphological changes that has been described as present in infants dying in crib death age range who had no morphological abnormalities. This is what James first referred as "molding and shaping" of the atrio-ventricular (AV) node and His bundle, a process never claimed as unique to crib death but that, on the contrary, must be considered a normal postnatal morphological change $[10,17,18]$. This postnatal morphogenesis is mediated by apoptotic death of myocytes in both the sinus node and the AV junctional tissue $[39,40]$. Since there is no associated inflammation or other indicators of necrosis, some authors have considered such changes as normal or harmless. A misunderstanding of this interpretation has come from two directions: first, those who conclude that a "normal" process could not be seen as pathological; and, second, those who are seeking a single or unique abnormality to blame for crib death. The problem here is that it is not correct to say that because something is normal that it is not necessarily dangerous. Since we do not all die during these ubiquitous changes, the changes usually are harmless.
This seems due to the fact that no additional other stressful events encountered in a baby's life (such as fever, vomiting or diarrhea and electrolytic unbalance) coincided with the period of postnatal morphogenesis, whereas either the cell death and otherwise innocuous events are harmless if they occur alone.

\subsection{Resorptive degeneration}

The AV node and His bundle undergo a remarkable postnatal morphogenesis, defined by James [17] in 1968 as "resorptive degeneration", consisting of degeneration, cell death and replacing in an orderly programmed way $[10,16-18,32,65]$. This term indicates a tidying-up process in which loose strands of surplus conducting tissue are gradually reabsorbed to change AV node and His bundle into their more smooth adult configuration $[10,17,41,66]$. The resorptive degeneration areas have been described as clusters of young fibroblasts depositing collagen caught in the central fibrous body, sometimes isolated from the "overdeveloped" specialized structures, sometimes adjacent to them, without association of inflammation nor massive necrosis or hemorrhage [1,17]. Matturri et al. [67] reported areas of resorptive degeneration in $97.10 \%$ of the crib death and in $75 \%$ of control cases, with a statistically significant difference comparing the two groups $(P<0.05)$. Similarly to James [17], Matturri et al. [67] have detected resorptive degeneration both in crib death and control cases, but they found that it is significantly more frequent in crib death than in controls cases $(P<0.05)$. James [18] stated that there is no clear correlation between the extent or presence of degeneration and the age at death. Similarly, Matturri et al. [67] found that the presence of resorptive degeneration resulted not statistically different in age-related subgroups $(P>0.05)$. James, in his original work [17], emphasized that the process is ubiquitous at the infancy period, being a normal phenomenon rather than a pathological one, but that ubiquity could not be read as synonymous with safety or stability $[10,68]$. In fact, it seems that this orderly normal process, if exaggerated, could provoke blocking disruption of the pathway itself, and if defective could leave in place some accessory communications between the AV pathway and the adjacent ordinary myocardium $[4,16,23,67]$. The James' studies have been confirmed by some authors $[1,4,14-16,22,23,42,43,67]$, while have been considered not conclusive by others $[11,21,33,44,45]$. Davies et al. [69] pointed out that there is not an association between resorptive degeneration and sudden infant death, being the process present equally in crib death and control cases. Valdes-Dapena et al. [44], Anderson et al. [33], Lie et al. [11] described fetal dispersion of the AV node without evidence of cell death, phagocytosis or replacement fibrosis. Thiene [70] concluded that the search needs to be continued for a better definition of what is normal and abnormal in the conduction system of the infant heart. It is to be underlined that the concept of "resorptive degeneration" remains a 
contentious issue [45]. In a commentary on one of our previous work [67], Anderson questioned the definition of "resorptive degeneration" itself [45].

\subsection{Dispersion or septation of the AV node and His bundle}

The dispersion or septation of the AV node and/or His bundle is characterized by fragmentation of the main node/bundle within the central fibrous body $[1,43,68,71]$. The consequences of this alteration should be intrahisian slowing of the conduction rate producing reentrants, increased automaticity, and paroxysmal block due to fractionation of the impulse transmission, ventricular arrhythmias and sudden death [68,72]. Matturri et al. [67] observed His bundle dispersion/septation in $33.33 \%$ of crib death and in $16.66 \%$ of explained death cases, without a statistically significant difference. Being present in both groups, therefore, Matturri et al. [67] and Suàrez-Mier and Aguilera [12] conclude that His bundle dispersion cannot be implicated as an unequivocal cause of crib death. Ho and Anderson [73] found His bundle dispersion and molding in a higher proportion of hearts from controls than from infants dying suddenly and unexpectedly. Matturri et al. [67] found AV node dispersion/septation in $7.24 \%$ of crib death cases, and in no explained death cases. Likewise for the septate/ dispersed His bundle, we retain that the consequences of this alteration could be a deceleration of the conduction speed with phenomenon of reentry, increased automatism, block due to the splitting of the impulse transmission, ventricular arrhythmias, and sudden death $[71,72]$.

The septation of the bifurcating His bundle is known also as anomalous bifurcation [1]. It was detected by Matturri et al. [67] in $13.04 \%$ of crib death cases and in no controls.

\subsection{Islands of conduction tissue in the central fibrous body}

The islands of conduction tissue in the central fibrous body, designated as persistent fetal dispersion, have been described as islands of the conduction system separated from the AV node and His bundle, dispersed in the central fibrous body, resembling the normal fetal pattern $[66,68,71]$. It has been suggested by James [61] that such islands could serve as suitable anatomic substrates for reentrant pathways, dissociation of the impulse conduction and paroxysmal tachycardias. If the dispersed fragments are separated from the AV node or His bundle but remain attached to the crest of the interventricular septum, their cytologic content and anatomic location would favor their function as parasystolic foci with either spontaneous or triggered automatic rhythms, serving as abnormal foci of automaticity $[61,66]$. Islands of conduction tissue in the fibrous body were detected by Matturri et al. [67] in $24.63 \%$ of crib death and in $15.38 \%$ of explained death cases, without statistically significant difference. Davies et al. [69] and Suàrez-Mier and Gamallo [71] postulated that fetal dispersion and His fragmentation can be a normal variation and must not be considered the anatomic substrate for arrhythmias and sudden death without electrocardiographic abnormalities.

\subsection{Mahaim fibers}

Mahaim fibers are specialized accessory pathways connecting the $\mathrm{AV}$ junction and the upper ventricular septum $[1,22,43,74]$. It seems that whenever the physiologic process of resorptive degeneration fails or slows down, some peripheral bundles of the conduction system remain connected to the common myocardial tissue of the ventricular septum, configuring the so-called Mahaim fibers $[1,16,22,23,66,74]$. These fibers, under particular conditions and/or neurovegetative stimuli, may cause potentially malignant junctional arrhythmias $[1,16]$. They have been previously described in cases of sudden infant death $[1,12,22,75,76]$. Buja et al. [76] reported the case of an infant dying of supraventricular tachycardia; his heart showed a Mahaim fiber in a setting of persistent fetal dispersion consistent with an anatomic substrate for a reentry circuit at the $\mathrm{AV}$ junction. Suàrez-Mier and Aguilera [12] found Mahaim fibers in nine of 55 crib death cases $(16.36 \%)$ and in no control cases, thus postulating that this type of accessory pathway may be responsible for death in some crib death cases. Matturri et al. [67] detected Mahaim fibers in $21.73 \%$ of crib death and in $8.3 \%$ of control cases, without a statistically significant difference between the two groups $(P>0.05)$. When there is a working accessory AV connection, the whole AV system or its junctional tract, can become part of a classical circuit of a tachycardic macroloop. Notoriously, the pre-excitation depends on the presence of AV accessory pathways where the impulse can diffuse in antegrade direction $[43,72]$.

\subsection{Cartilaginous meta-hyperplasia of the central fibrous body}

The fibroblasts of the central fibrous body seem to have pluripotential nature, although the functional meaning of this alteration is still unknown $[67,68]$. In normal circumstances they produce dense collagen but there are examples of cartilage or sometimes bone present in the central fibrous body [68]. It is reasonable that the fibroblasts of the fibrous body, essential to complete the morphogeny of the adjoining AV node and His bundle, can sometimes work improperly becoming both hyperactive and inactive. In the case in which they produce mediums different from the collagen, they could also present a metaplastic transformation. What can induce such metaplasia is completely unknown, even if it could be logically suspected that they are a consequence of physical stress, ischemia or other unknown factors [66]. For example, the synthesis of the DNA of the cartilaginous cells is stimulated by oscillating electric fields [77], but it can be supposed that such an effect exists in the fibrous body or near to it [66]. Cartilaginous meta-hyperplasia of 
the central fibrous body has already been described in cases of cardiac sudden death $[1,66,67]$. Since the AV node lies directly upon the central fibrous body and the His bundle courses through it, they both seem to be in some jeopardy by proximity when an alteration of the central fibrous body is present $[66,68]$. It seems that a central fibrous body with cartilaginous meta-hyperplasia can potentially provoke a compression on the His bundle and on the conduction system in many crib death cases [78]. Ferris and Aherne [79] described the cases of two infants dying unexpectedly with the postmortem findings of nodules of fibrocartilage within the central fibrous body adjacent to the His bundle and AV node. Matturri et al. [67] detected cartilaginous meta-hyperplasia of the central fibrous body in $5.79 \%$ of crib death and in $4.16 \%$ of explained death cases. James [61] affirmed that cartilaginous or bony metaplasia in cases of sudden and unexpected death, originated from the pluripotential fibroblasts of the fibrous body have been observed in cases of sudden and unexpected death but their role to cause the death has not yet been entirely understood.

\subsection{Hemorrhage of the cardiac conduction system}

Hemorrhage of the conducting tissue is generally considered present when red blood cells are seen in the intercellular spaces [33]. Matturri et al. [67] detected hemorrhage in the atrio-ventricular junction in $15.94 \%$ of crib death cases, while hemorrhage was absent in controls, and was not seen in the sinus node of all cases. Since almost all of our crib death cases underwent emergency resuscitative effort, including external cardiac massage, Rossi and Matturri [80] considered it as occurred after death, due to injury during attempted resuscitation efforts. Matturri et al. [67] state that it seems difficult to distinguish between junctional hemorrhages occurring during life or immediately after death. Other investigators [11,12,33], considering a larger number of controls, found hemorrhagic lesions present in both groups. Jankus [34], in his report of three crib death and three explained death cases, found hemorrhage exclusively in crib death cases.

\subsection{Left sided His bundle}

Bharati et al. [81] observed left sided His bundle significantly more commonly in crib death $(53.3 \%)$ than in explained death $(25 \%)$ cases, suggesting that this may be a factor promoting crib death. Massing and James [60] found this position in $62.5 \%$ of normal human hearts of various age. Left sided His bundle has been described in association with sudden death in previously healthy people $[72,82]$ and in asthmatics [83]. Matturri et al. [67] detected left sided His bundle in $20.29 \%$ of crib death and in $8.3 \%$ of controls, without a statistically significant difference. Rossi [84] reported that intramural left bundle branch is comparatively more vulnerable by impaired blood supply through the nutrient arteries.

\subsection{Cardiac conduction system hypoplasia}

Studies of the cardiac conduction system in crib death are usually directed to the AV node and His bundle, but it seems that also the sinus node may be involved. Ho et al. [85] described three cases of hypoplastic sinus node in perinatal patients with cardiac arrhythmia immediately before death. They discussed the hypoplasia of the sinus node as due to an arrest or defect in development rather than an active degenerative process. Kozakewich et al. [86], examining the sinus node of 30 crib death and 18 explained death cases, found no difference in size between the two groups, while found intimal lesions of the sinus node intranodal artery in three cases of crib death. Matturri et al. [67] found the sinus node hypoplasia present in $5.79 \%$ of crib death cases, and absent in control cases.

Matturri et al. [67] found His bundle hypoplasia present in one of the 69 crib death cases (1.45\%) and in no controls.

\subsection{AV node and/or His bundle dualism}

The AV node and His bundle present a "dualism" when appear stratified into two portions by interposition of a fibrous diaphragm, so configuring the morphological basis of dual AV pathways $[15,67,87]$. Matturri et al. [67] found $\mathrm{AV}$ node dualism present in two cases of crib death $(2.89 \%)$, and in none of control cases, while His bundle dualism was present in $2.89 \%$ of crib death and in $4.16 \%$ of explained death cases. Bharati et al. [88] described a case of distinct AV node-like structure on the parietal wall of the right atrium in a patient with a history of paroxysmal supraventricular tachycardia.

\subsection{Zahn node}

The Zahn node $[56,89,90]$ is also known as the coronary sinus node because it is situated near the myocardium of the coronary sinus outlet [56]. Doerr [91] in 1957 as a picture of Zahn node presented a large illustration of a Yshaped bundle of loosely arranged myocardial fibers, embracing a neurovegetative ganglion and protruding from an "atrial tail" of the AV node, close to the coronary sinus [56]. Doerr and Schiebler [92] recognized that it is difficult to decide whether the coronary sinus node could be considered as a separate entity of the conducting system or only as the dorsal atrial part of the AV node [56]. Matturri et al. [67], among the 69 crib death cases analyzed, described a case of Zahn node, which was previously reported and discussed as the plausible substrate for reentry tachyarrhythmias [93].

\subsection{Fibromuscular hyperplasia of the cardiac conduction system arteries}

The fibromuscular hyperplasia or dysplasia [94] of the sinus node and/or AV node arteries has been described as a 
cause of death in young people and adults $[95,96]$. Anderson and Hill [97], analyzing 40 victims of crib death, found five cases $(12.5 \%)$ with marked thickness of the AV artery and a case with marked thickness of the sinus node artery. The authors have hypothesized that this thickness is the cause of an ischemia to the conducting tissue with consequent cardiac arrhythmias and heart block. Only in one of our 69 cases of crib death (1.45\%) a fibromuscular hyperplasia of the AV artery was detected. This percentage is inferior to that found by Anderson and Hill (12.5\%) [97] and is more similar to that found by Suàrez-Mier and Aguilera (1.8\%) [12].

\subsection{Apoptosis of the cardiac conduction system}

The programmed cell death named apoptosis is of particular interest [98-102]; its unpredictable occurrence could play a role in the pathogenesis of crib death $[10,40,51,98]$. Matturri et al. [98], in a study on eight crib death and three control hearts, found that the apoptotic indices (AI) in AV node, His bundle, bundle branches, did not to have statistically significant differences $(P>0.05)$, while in the resorptive degeneration areas the AI resulted higher in control than crib death group. In almost all cases, TUNEL labeling was detected in peripheral region of the AV node, close to the atrial myocardium [98]. This was in agreement with the observations of James [103] who described that the AV node, during the postnatal morphogenesis, becomes smaller, toward its adult configuration, being reabsorbed mainly at its periphery, almost always along its left margin and that apoptosis is a major and possibly the main mechanism by which cell death occurs during the postnatal morphogenesis of the cardiac conduction system $[10,39]$. The postnatal morphogenesis of the sinus node by apoptosis occurs generally in the same time period (first year of life) as the postnatal morphogenesis of the AV node and His bundle. This involves multifocal cell death by apoptosis and could serve to distort further the normal rhythm of baby's heart. While the changes in the AV node and His bundle are principally smoothing of the margins of these two structures and eliminating surplus tissue that can be dangerous if not removed, the changes in the sinus node are quite different, amounting more or less to a total restructuring of the interior of the sinus node itself: the fetus and the infant have sinus nodes composed primarily of $\mathrm{P}$ cells whereas the sinus node of the adult human always contains a mixture of transitional cells and $\mathrm{P}$ cells. These changes occur either by transformation of some of the $\mathrm{P}$ cells to transitional cells or by death of $\mathrm{P}$ cells to be replaced by transitional cells, perhaps migrating in from the margins of the sinus node $[10,39,40]$. Cardiac arrhythmias, such as atrial fibrillation or atrial flutter, as well as distortions in sinus rhythm, including episodes of sinus arrest or tachycardia or ectopic beading, are facilitated by impaired activity of the sinus node during its molding [39,40]. It has been suggested that apoptosis of the cardiac conduction system could be a process favoring electrical instability in two opposite ways. A defective apoptosis could leave in place some accessory communication between the AV pathway and the adjacent ordinary myocardium, and would leave the sinus node in its fetal configuration, eliminating the beneficial evolution into an appropriate mixture and distribution of P cells among transitional cells $[10,16]$. An exaggerated apoptosis, could provoke blocking disruption of the pathway itself, and can disfigure the sinus node structure or even completely destroy it $[1,10,104,105]$. Kajstura et al. [106], in their study of programmed cell death during cardiac maturation in rats, found that myocyte cell death was absent in the fetal heart while affected the myocardium postnatally, particularly the right ventricle.

\subsection{Long $Q T$ syndrome}

A notable example of multifocal apoptotic degeneration of the sinus node occurs in victims dying of the long-QT syndrome, a clinical entity characterized by sinus bradycardia $[107,108]$. Sudden unexpected death is one of the clinical characteristics of the long-QT syndrome and has often been documented to be mediated by lethal ventricular arrhythmias. It is logical to anticipate that the normal occurrence of apoptotic cell death during postnatal morphogenesis of the sinus node will periodically distort or suppress normal sinus rhythm [105]. Moreover, in the long-QT syndrome apoptotic destruction involves not only the myocytes of the sinus node but also many local nerves and ganglia $[107,108]$.

The QT prolongation could be dangerous in babies and a possible cause of their fatal arrhythmia [109,110], but solid evidence of its occurrence is still controversial. The capricious nature of episodic QT prolongation documented in human infants poses difficulties in demonstrating lethal cardiac electrical instability [107].

In 1998 Schwartz et al. [13], in their 19-year prospective study, performed follow up electrocardiograms in an unselected population of over 33,000 infants, finding that congenital prolongation of the QT interval accounts for a portion of the crib death cases. However, Schwartz et al. admitted that the long-QT syndrome can account for only a fraction of the crib death cases, and precise quantification of this fraction remains difficult despite the data obtained from their large epidemiologic study [13,111]. Guntheroth and Spiers [112] state that submitting all the infants and newborns to an electrocardiogram screening would be an ineffectual waste of medical resources and it would cruelly alarm thousands of parents.

Viskin et al. [113] recommend genetic screening in every case of probable long-QT syndrome, but state that positive result will confirm the diagnosis and that, however, no mutations are found in many patients with a definite diagnosis of long-QT syndrome, so a negative result is not very helpful. In any case, genetic testing might take months, and the patient needs treatment [113]. 
Schwartz et al. [13] in crib death cases did not perform a postmortem histopathological study, nor gave importance to it [113]. This is in contrast with other authors who considered instead the autopsy very important in every case of sudden death in infancy $[67,88,94,107,108,114]$.

\section{Conclusions}

Sudden death of a baby is one of life's most tragic events. Although a wide variety of possible explanations have been proposed, the role for fatal electrical instability of the heart as the final common pathways remains infrequently considered. In this review evidence is presented to demonstrate why we must place the heart's role higher among our considerations: in infant's heart there is an electrical vulnerability due to the postnatal molding of the cardiac conduction system $[32,41,42]$. This postnatal morphogenesis is mediated by apoptotic death of myocytes in both the sinus node and the AV junctional tissues [10,98]. However, according to Anderson, the significance of "resorptive degeneration" has still to be established [45].

Despite the non-specificity of most of the cardiac conduction findings in crib death, it is believe that they, in association with altered neurovegetative stimuli $[13,31]$, could underlie potentially malignant arrhythmias, providing a morphologic support for the cardiac concept of crib death [62]. It seems, in fact, a crucial point in causing crib death the necessary coexistence of other concomitant events (such as fever, vomiting or diarrhea and electrolytic unbalance) when they coincide with active cell death in the conduction system, whereas either the cell death and otherwise innocuous events are harmless if they occur alone. It is therefore important that we recognize as many of these contributing causes, including sleeping position, and intervene in as many of them as possible.

The necessary cardiac, as well the neuro-pathological [115-117], study, addressed to the identification of the crib death's morphological substrate, requires the examination of a large amount of cases with homogeneous and standardized criteria. A complete examination of the cardiac conduction system on serial sections allows an objective dimensional and architectural evaluation of all the pertinent anatomical portions of the conducting tissue. This requires a great amount of sections and the systematic application of histologic (hematoxylin/eosin, trichromic Heidenhain) and immunohistochemical (apoptosis, etc.) techniques. Moreover, such complete examination of the cardiac conduction system requires the work of properly trained histotechnicians. Suàrez-Mier and Aguilera [12] state that the procedure for the simplified examination of the cardiac conduction system allows as well the evaluation of all the different structures, examining only specific levels. Should be underlined that, due to conduction system architectural variability, wrong indications on conducting tissue's struc- ture and extension can depend on the examination of single and casual sections. Furthermore, a finding of accessory fibers' absence could depend on the restrictive analysis of part of the conducting tissue during the cardiac sampling. On the basis of these considerations, we suggest that the autopsy protocol for the SIDS victims, already internationally approved [118], should include the examination of the cardiac conduction system according to the above described guidelines. These will allow an accurate and standardized study of the conducting tissue, in addition to the examination of the autonomic nervous system [119]. Our point of view has been challenged by Anderson [45] who does not believe that considerable information would be gained if all pathologists expanded their protocols of investigation to include study of conduction system in all infants dying suddenly and unexpectedly. In a commentary on one of our previous work [67], he raised various questions concerning the validity of a routine examination of the conduction system in suspected cases of crib death [45]. The fact that a significant decline in the incidence of crib death has already been achieved by simple strategies, such as putting infants to sleep on their back, or by mothers reducing their smoking habits $[5,6]$, argues against the likelihood of cardiac conduction findings being causative for the entity of sudden unexpected death in infancy [45]. Anderson [45] states that the effort required for a routinely investigation of the cardiac conduction system must not be underestimated. While he underlines that examination of the conduction system is a tedious and painstaking undertaking, both for the technician and the pathologist, he admits that serial sectioning of the blocks of tissue which contain the conduction tissues is mandatory, that such efforts are not to be discouraged, and that there is much we still need to establish concerning the arrangement of the conduction tissues in infant hearts [45].

Much meticulous clinical-pathologic correlative work remains to be done in identifying the herein described conduction system abnormalities that might play a lethal role in causing crib death [67]. The search shall be continued for a better definition of what is normal or abnormal in the conducting tissue of the infant's heart. Under the light of clinico-physiological findings on infants dying of crib death, as well as in those so-called "at risk", a deeper insight is needed by microscopical research (histology, ultrastructure, immuno-histochemistry), the extremely specialized of which requires adequately expertise centers.

\section{Acknowledgements}

This work was supported by the Pegasus Fund of the University of Texas Medical Branch, and by Lombardy Region project 49210-24.3.00: "Program of Research and Intervention for the Reduction of the Risk of Sudden Infant Death and Unexpected Fetal Death". 


\section{References}

[1] Rossi L, Matturri L. Anatomohistologic features of the heart's conduction system and innervation in SIDS. In: Rognum TO, editor. Sudden infant death syndrome. New trends in the nineties, Oslo: Scandinavian University Press, 1995. pp. 207-12.

[2] Berry PJ. Pathological findings in SIDS. J Clin Pathol (Suppl) 1992;45:11-6.

[3] Boyle FM, Vance JC, Najman JM, Thearle MJ. The mental health impact of stillbirth, neonatal death or SIDS: prevalence and patterns of distress among mothers. Soc Sci Med 1996;43:1273-82.

[4] Rossi L, Matturri L. Anatomohistological features of sudden infant death. New Trends Arrhythmias 1991;6:135-42.

[5] Gibson E, Fleming N, Fleming D, et al. Sudden infant death syndrome rates subsequent to the American Academy of Pediatrics supine sleep position. Med Care 1998;36:938-42.

[6] Moon RY, Omron R. Determinants of infant sleep position in an urban population. Clin Pediatr 2002;41:569-73.

[7] Pinholster G. Multiple "SIDS" case ruled murder. Science 1995; 268:494

[8] Shannon DC. Murder and video surveillance. Pediatrics 1998; 102:160.

[9] Emery JL. Child abuse, sudden infant death syndrome, and unexpected infant death. Am J Dis Child 1993;147:1097-100.

[10] James TN. Normal and abnormal consequences of apoptosis in the human heart. From postnatal morphogenesis to paroxysmal arrhythmias. Circulation 1994;90:556-73.

[11] Lie JT, Rosenberg HS, Erickson EE. Histopathology of the conduction system in the sudden infant death syndrome. Circulation 1976; $53: 3-8$.

[12] Suàrez-Mier MP, Aguilera B. Histopathology of the conduction system in sudden infant death. Forensic Sci Int 1998;93:143-54.

[13] Schwartz PJ, Stramba-Badiale M, Segantini A, et al. Prolongation of the QT interval and the sudden infant death syndrome. New Engl J Med 1998;338:1709-14.

[14] Ottaviani G, Goisis M, Ramos SG, Matturri L. Dispersione del tessuto giunzionale e sue conseguenze in un caso di morte improvvisa del lattante. Cardiologia 1998;43:737-9.

[15] Ottaviani G, Rossi L, Bondurri A, Ramos SG, Matturri L. Morte improvvisa del lattante: un caso di sdoppiamento del nodo atrioventricolare. Riv Ital Pediatr 1998;24:1165-7.

[16] Ottaviani G, Ramos SG, Matturri L. Defective "resorptive degeneration" of the heart's conduction system and sudden infant death syndrome. Ann Esp Ped (Suppl) 1997;92:53, Abstract.

[17] James TN. Sudden death in babies: new observation in the heart. Am J Cardiol 1968;22:479-506.

[18] James TN. Crib death. J Am Coll Cardiol 1985;5:1185-7.

[19] Anderson WR, Edland JF, Schenk EA. Conducting system changes in the sudden infant death syndrome. Am J Pathol 1970;59:35a, Abstract.

[20] Ferris JAJ. Hypoxic changes in conducting tissue of the heart in sudden death in infancy syndrome. Br Med J 1973;2:23-5.

[21] Valdès-Dapena M. Are some crib deaths sudden cardiac deaths? J Am Coll Cardiol 1985;5:1113B-7B.

[22] Rossi L, Matturri L. Clinicopathological approach to cardiac arrhythmias: a color atlas, Turin: Centro Scientifico Torinese, 1990.

[23] Guareschi M, Ottaviani G, Ramos SG, Matturri L. Morte improvvisa del lattante (SIDS): un caso con vie accessorie e resorptive degeneration. Pathologica 1998;90:294-7.

[24] Martinez FD. Sudden infant death syndrome and small airway occlusion: facts and hypothesis. Pediatrics 1991;87:190-8.

[25] Guntheroth WG, Spiers PS. Are bedding and rebreathing suffocation a cause of SIDS? Pediatr Pulmonol 1996;22:335-41.

[26] Widdicombe JG, Tatar M. Upper airway reflex control. Ann N Y Acad Sci 1988;533:252-61.

[27] Jeffery HE, Page M, Post EJ, Wood AK. Physiological studies of gastro-oesophageal reflux and airway protective responses in young animal and human infant. Clin Exp Pharmacol Physiol 1995;22: 544-9

[28] Kinney HC, Filiano JJ, Harper RM. The neuropathology of the sudden infant death syndrome. A review. J Neuropathol Exp Neurol 1992;51:115-26.

[29] Matturri L, Ottaviani G, Ramos SG, Biondo B, Rossi L. Discrete T-lymphocytic leptomeningitis of the ventral medullary surface in a case of sudden unexpected infant death. Adv Clin Pathol 1998; 2:313-6.

[30] Matthews TG. The autonomic nervous system - a role in sudden infant death syndrome. Arch Dis Child 1992;67:654-6.

[31] Matturri L, Biondo B, Mercurio P, Rossi L. Severe hypoplasia of medullary arcuate nucleus: quantitative analysis in sudden infant death syndrome. Acta Neuropathol 2000;99:371-5.

[32] James TN. Sudden death of babies. Circulation 1976;53:1-2.

[33] Anderson RH, Bouton J, Burrow CT, Smith A. Sudden death in infancy: a study of cardiac specialized tissue. Br Med J 1974;2: $135-9$.

[34] Jankus A. The cardiac conduction system in sudden infant death syndrome: a report on three cases. Pathology 1976;8:275-80.

[35] Bharati S, Bauernfiend R, Scheinman M, et al. Congenital abnormalities of the conduction system in two patients with tachyarrhythmias. Circulation 1979;59:593-606.

[36] Balogh K, Ferris JA, Aherne WA. Fibrocartilage in the heart. Lancet 1971;1:802-3.

[37] Kendeel SR, Ferris JAJ. Fibrosis of the conducting tissue in infancy. J Pathol 1975;117:123-31.

[38] Ferris JAJ. Cot death-why not the heart? Med Sci Law 1972;12: $173-7$.

[39] James TN. Apoptosis in congenital heart disease. Coron Artery Dis 1997;8:599-616.

[40] James TN. Normal and abnormal consequences of apoptosis in the human heart. Annu Rev Physiol 1998;60:309-25.

[41] James TN. Cardiac conduction system: fetal and postnatal development. Am J Cardiol 1970;25:213-26.

[42] Marino TA, Kane BM. Cardiac atrio-ventricular junctional tissue in hearts from infants who died suddenly. J Am Coll Cardiol 1985; 5:1178-84.

[43] Rossi L, Matturri L. Cardiac conduction and nervous system in health, disease and sudden death: an anatomoclinical overview. Osp Maggiore 1995;89:239-57.

[44] Valdes-Dapena MA, Greene M, Basavanand N, Catherman R, Truex RC. The myocardial conduction system in sudden death in infancy. New Engl J Med 1973;289:1179-80.

[45] Anderson RH. Sudden and unexpected death in infancy and the conduction system of the heart. Cardiovasc Pathol 2000;9:147-8.

[46] Wren C. Mechanism of fetal tachycardia. Heart 1998;79:536-9.

[47] Ottaviani G, Rossi L, Ramos SG, Matturri L. Pathology of the heart and conduction system in a case of sudden death due to a cardiac fibroma in a 6-month-old child. Cardiovasc Pathol 1999;8:109-12.

[48] Ottaviani G, Matturri L, Rossi L, James TN. Crib death: further support for the concept of fatal cardiac electrical instability as the final common pathway. Proceedings of the 7th SIDS International Conference, Florence. 2002, p. 66.

[49] Valdes Dapena M, Huff D. Perinatal autopsy manual. Washington, DC: Armed Forces Institute of Pathology, 1983.

[50] Gilbert-Barnes E. Potter's pathology of the fetus and infant. St. Louis: Mosby Year Book, 1997.

[51] Ottaviani G, Matturri L, Lavezzi AM, Rossi L, James TN. Postnatal apoptosis of the cardiac conduction system in crib death: preliminary results. Proceedings of the 7 th International Conference on SIDS, Florence. 2002, p. 132.

[52] Filiano JJ, Kinney HC. Arcuate nucleus hypoplasia in the sudden infant death syndrome. J Neuropathol Exp Neurol 1992;51:394-403.

[53] Ramos SG, Matturri L, Biondo B, Ottaviani G, Rossi L. Hyperplasia of the aorticopulmonary paraganglia: a new insight into the patho- 
genesis of sudden infant death syndrome? Cardiologia 1998;43: $953-8$.

[54] Heath D, Khan Q, Smith P. Histopathology of the carotid bodies in neonates and infants. Histopathology 1990;17:511-20.

[55] Rossi L, Varesi C, Matturri L. Fondamenti tecnico-scientifici sul sistema di conduzione e nervoso cardiaco in ordine alla problematica della morte improvvisa cardiaca. Pathologica 1994;86:436-40.

[56] Rossi L. Histopathologic features of cardiac arrhythmias, Milan: Casa Editrice Ambrosiana, 1969.

[57] Rossi L. "Salvage the pacemaker" at autopsy. Am Heart J 1978;95: $540-1$.

[58] Matturri L. Proceedings of the International Symposium on the SIDS (Sudden Infant Death Syndrome) and Region Lombardy Project on the Risk Reduction for the Sudden Death of Infant and Fetus, Milan, 4-5 October 1999.

[59] James TN. Morphology of the human atrioventricular node, with remarks pertinent to its electrophysiology. Am Heart J 1961;62: $756-71$.

[60] Massing GK, James TN. Anatomical configuration of the His bundle and bundle branches in the human heart. Circulation 1976; 53:609-21.

[61] James TN. Normal variations and pathologic changes in structure of the cardiac conduction system and their functional significance. J Am Coll Cardiol 1985;5:71B-8B.

[62] Matturri L, Martini I, Rossi L. SIDS nell'area di Milano: studio epidemiologico di 38 casi. Ann Inst Super Sanità 1993;29:457-63.

[63] Kinney HC, Filiano JJ, Sleeper LA, Mandell F, Valdes-Dapena M, White WF. Decreased muscarinic receptor binding in the arcuate nucleus in sudden infant death syndrome. Science 1995;269: 1446-50.

[64] Matturri L, Minoli I, Lavezzi AM, Cappellini A, Ramos S, Rossi L. Hypoplasia of medullary arcuate nucleus in unexpected late fetal death (stillborn infants): a pathologic study. Pediatrics 2002; 109:E43.

[65] Harper RM, Bandler R. Finding the failure mechanism in sudden infant death syndrome. Nat Med 1998;4:157-8.

[66] James TN. The Mikamo lecture. Structure and function of the AV junction. Jpn Circ J 1983;47:1-47.

[67] Matturri L, Ottaviani G, Ramos SG, Rossi L. Sudden infant death syndrome (SIDS): a study of cardiac conduction system. Cardiovasc Pathol 2000;9:137-45.

[68] James TN, Marshall TK. De subitaneis mortibus. XVIII. Persistent fetal dispersion of the atrioventricular node and His bundle within the central fibrous body. Circulation 1976;6:1026-34.

[69] Davies MJ, Anderson RH, Becker AE. The conduction system of the heart, London: Butterworths, 1983. pp. 301-23.

[70] Thiene G. Problems in the interpretation of cardiac pathology in reference to SIDS. Ann N Y Acad Sci 1988;533:191-9.

[71] Suàrez-Mier P, Gamallo C. Atrioventricular node fetal dispersion and His fragmentation of the cardiac conduction system in sudden cardiac death. J Am Coll Cardiol 1998;32:1885-90.

[72] Bharati S, Lev M. Congenital abnormalities in the conduction system in sudden death in young adults. J Am Coll Cardiol 1986; 8:1096-104.

[73] Ho SY, Anderson RH. Conduction tissue and SIDS. Ann N Y Acad Sci 1988;533:176-90.

[74] Rossi L. The pathologic basis of cardiac arrhythmias. Cardiol Clin 1983;1:13-37.

[75] Cohle SD, Lie JT. Pathologic changes of the cardiac conduction tissue in sudden unexpected death. A review. Pathol Ann 1991; 2:33-57.

[76] Buja GF, Corrado D, Pellegrino PA, Nava A, Thiene G. Fatal paroxysmal supraventricular tachycardia in an infant. Chest 1986; 90:145-6.

[77] Rodan GA, Bourret LA, Norton LA. DNA synthesis in cartilage cells is stimulated by oscillating electric fields. Science 1978; 199:690-2.
[78] Rossi L. Histopathology of the cardiac conduction system in the problem of arrhythmogenic SIDS. Proceedings of the 18th International Symposium on Neonatal Intensive Care, Milan. 4-10 November 1998, p. 75.

[79] Ferris JA, Aherne WA. Cartilage in relation to the conducting tissue of the heart in sudden death. Lancet 1971;1:64-6.

[80] Rossi L, Matturri L. His bundle haemorrhage and external cardiac massage: histopathological findings. Br Heart J 1988;59:586-7.

[81] Bharati S, Krongrad E, Lev M. Study of the conduction system in a population of patients with sudden infant death syndrome. Pediatr Cardiol 1985;6:29-40.

[82] Bharati S, Bauernfeind R, Miller L, Strasberg B, Lev M. Sudden death in three teenagers: conduction system studies. J Am Coll Cardiol 1983;1:879-86.

[83] Bharati S, Lev M. Conduction system findings in sudden death in young adults with a history of bronchial asthma. J Am Coll Cardiol 1994;23:741-6

[84] Rossi L. Intramural ramification of the left bundle branch. Am Heart J 1978;96:271-2.

[85] Ho SY, Mortimer G, Anderson RH, Pomerance A, Keelings JW. Conduction system defects in three perinatal patients with arrhythmia. Br Heart J 1985;53:158-63.

[86] Kozakewich HPW, McManus BM, Vawter G. The sinus node in sudden infant death syndrome. Circulation 1982;65:1242-6.

[87] Rossi L, Thiene G. Arrhythmologic pathology of sudden cardiac death, Milan: Casa Editrice Ambrosiana, 1983. pp. 83-4.

[88] Bharati S, Dreifus L, Bucheleres G, et al. The conduction system in patients with a prolonged QT interval. J Am Coll Cardiol 1985;6: $1110-9$

[89] Waldo AL, James TN. A retrospective look at A $-\mathrm{V}$ nodal rhythms (A Zahn). Circulation 1973;47:222-4.

[90] Zahn A. Experimentelle untersuchungen über die reizbildung im atrioventrikularnoten und sinus coronarius. Zentraubl Physiol 1912;26:495.

[91] Doerr W. Die morphologie des reizleitungssystemes ihre orthologie und pathologie. In: Spang K, editor, Rhythmusstörungen des herzens, vol. 11, Stuttgart: Thieme, 1957. p. 16.

[92] Doerr W, Schiebler TH. Pathologische anatomie des reizleitungssystems. In: Bargmann W, Doerr W, editors, Das herz des menschen, Stuttgart: Thieme, 1963.

[93] Matturri L, Nappo A, Varesi C, Martini I, Rossi L. Dualismo del nodo atrioventricolare per la presenza del nodo del seno coronarico di Zahn in un caso di morte improvvisa del lattante (SIDS). Riv Ital Pediatr 1997;23:130-3.

[94] James TN. Congenital disorders of cardiac rhythm and conduction. J Cardiovasc Electrophysiol 1993;4:702-18.

[95] James TN, Marshall TK. De subitaneis mortibus. XVII. Multifocal stenoses due to fibromuscolar dysplasia of the sinus node artery. Circulation 1976;53:736-42.

[96] James TN, Froggat P, Marshall TK. Sudden death in young athletes. Ann Int Med 1967;67:1013-21.

[97] Anderson KR, Hill RW. Occlusive lesions of cardiac conducting tissue arteries in sudden infant death syndrome. Pediatrics 1982; 69:50-2.

[98] Matturri L, Ottaviani G, Lavezzi AM, Turconi P, Cazzullo A, Rossi L. Expression of apoptosis and proliferating cell nuclear antigen (PCNA) in the cardiac conduction system of crib death (SIDS). Adv Clin Pathol 2001;5:79-86.

[99] Saunders JW. Death in embryonic systems. Science 1966;154: $604-12$

[100] Hockenbery D. Defining apoptosis. Am J Pathol 1995;146:16-8.

[101] Cummings MC, Winterford CM, Walker NI. Apoptosis. Am J Surg Pathol 1997;21:88-101.

[102] James TN. Complex causes of fatal myocardial infarction. Circulation 1997;96:1696-700.

[103] James TN. Change and sudden death. J Am Coll Cardiol 1983; $1: 164-83$. 
[104] James TN, St. Martin E, Willis III PW, Lohr TO. Apoptosis as a possible cause of gradual development of complete heart block and fatal arrhythmias associated with absence of the AV node, sinus node and internodal pathways. Circulation 1996;93:1424-38.

[105] James TN, Nichols MM, Sapire DW, Di Patre PL, Lopez SM. Complete heart block and fatal right ventricular failure in an infant. Circulation 1996;93:1588-600.

[106] Kajstura J, Mansukhani M, Cheng W, et al. Programmed cell death and expression of the protooncogene bcl-2 in myocytes during postnatal maturation of the heart. Exp Cell Res 1995;219:110-21.

[107] James TN. Long reflections on the QT interval: the sixth annual Gordon K. Moe lecture. J Cardiovasc Electrophysiol 1996;7: $738-59$.

[108] James TN, Froggatt P, Atkinson Jr W, et al. De subitaneis mortibus. XXX. Observations on the pathophysiology of the QT syndromes with special reference to the neuropathology of the heart. Circulation 1978;57:1221-31.

[109] Guntheroth WG. The QT interval and sudden infant death syndrome. Circulation 1982;66:502-4.

[110] Southall DP, Arrowsmith WA, Stebbins V, Alexander JR. QT interval measurements before sudden infant death syndrome. Arch Dis Child 1986;61:327-33.

[111] Schwartz PJ, Priori S, Dumaine R, et al. Brief report: a molecular link between the sudden infant death syndrome and the long-QT syndrome. New Engl J Med 2000;343:262-7.
[112] Guntheroth WG, Spiers PS. Prolongation of the QT interval and the sudden infant death syndrome. New Engl J Med 1998;339:1161-3.

[113] Viskin S, Fish R, Roth A, Schwartz PJ, Belhassen B. QT or not QT? New Engl J Med 2000;343:352-6.

[114] Rossi L, Matturri L. Neuronal degeneration localized in the thoracic spinal cord sympathetic center in a case with prolonged QT interval. G Ital Cardiol (Suppl) 1998;28:535-7.

[115] Matturri L, Biondo B, Suàrez-Mier MP, Rossi L. Brainstem lesions in the sudden infant death syndrome: variability in the hypoplasia of the arcuate nucleus. Acta Neuropathol 2002;104:12-20.

[116] Matturri L, Ottaviani G, Ramos SG, Rossi L. SIDS "gray zone" disclosed only by serial sections study of the brainstem and cardiac conduction system. In: Proceedings of the 7th International Conference on SIDS. 2002, p. 134.

[117] Matturri L, Ottaviani G, Rossi L. Sudden and unexpected infant death due to an hemangioendothelioma located in the medulla oblongata. Adv Clin Pathol 1999;3:29-33.

[118] Krous H. Instruction and reference manual for the international standardized autopsy protocol for sudden unexpected infant death. J SIDS Infant Mortal 1996;1:203-46.

[119] Matturri L, Lavezzi AM, Ottaviani G, Alfonsi G, Crippa M, Rossi L. Anatomo-pathological techiniches for the study of brainstem in sudden infant death syndrome (SIDS) and unexpected late fetal stillbirth. In: Proceedings of the 7th SIDS International Conference, Florence, 2002, p. 131-2. 